\title{
Code choice in the Chinese as a foreign language classroom
}

\author{
Danping Wang ${ }^{1 *}$ and Andy Kirkpatrick ${ }^{2}$
}

\author{
* Correspondence: dpwang@ied. \\ edu.hk \\ 'Department of English, the Hong \\ Kong Institute of Education, 10 Lo \\ Ping Road, New Territories, Hong \\ Kong \\ Full list of author information is \\ available at the end of the article
}

\begin{abstract}
The large influx of Chinese language learners into the People's Republic of China from different countries shapes the Chinese as a foreign language classroom as a multilingual and multinational domain. However, how Chinese language teachers perceive their choice of codes for teaching and communicating with international Chinese language learners remains an under-researched area. To investigate Chinese language teachers' language beliefs toward code choice in teaching Chinese as a foreign language, 24 Chinese language teachers from four universities in Beijing were invited to participate in this study. Findings indicated that although Chinese language teachers endeavored to abide by a Chinese-only principle, English was regularly and strategically employed as an international lingua franca (English as a lingua franca, ELF) for explanatory, managerial and interactive functions. The study concluded by proposing an "ELF pedagogy" for Chinese language teachers to consider in increasingly multilingual classrooms.
\end{abstract}

Keywords: Chinese as a foreign language, English as a lingua franca, Sinophone identity, code choice, multilingual classroom

\section{Background}

While Chinese has been taught and studied as a first language for millennia, its status as a second and foreign language is more recent, though it does count a history of some centuries in that regard (Lo Bianco 2007; 2011,). Research in the field is also fairly recent and connections are being developed between the varied contexts of teaching and learning, for example as a second language to minority groups in the People's Republic of China (Hu and Alsagoff 2010; Zhou and Sun 2004) and Taiwan (Chen and Hsin 2011); in post-colonial contexts such as Singapore (Tse and Tan 2011) and Hong Kong (Shum, Tsung and Gao 2011 “Teaching and learning (through) Putonghua: From the perspective of Hong Kong teachers"; Shum, Gao, Tsung and Ki 2011 "South Asian students' Chinese language learning in Hong Kong: Motivations and strategies"); and as a heritage and community language in the diasporas across the world, such as the United States (Xiao Yun 2011; Xing 2009; Chen, Wang and Cai 2010) and Britain (Li and Zhu 2011; Li 2011 "Moment Analysis and translanguaging space: Discursive construction of identities by multilingual Chinese youth in Britain"). However, few empirical studies (Yu 2010; Wang 2010 "A study of English as a lingua franca in teaching Chinese to speakers of other languages") have been conducted on the teaching of Chinese to multilingual international students within China. In the context of

\section{Springer}

(C) 2012 Wang and Kirkpatrick; licensee Springer. This is an Open Access article distributed under the terms of the Creative Commons Attribution License (http://creativecommons.org/licenses/by/2.0), which permits unrestricted use, distribution, and reproduction in any medium, provided the original work is properly cited. 
teaching Chinese as a foreign language in China (henceforth CFL), McDonald (2011) has commented that, "although it has currently constituted aims to give students access to Chinese language and culture, too often its practical outcome is to prevent foreigners from learning to use the language properly" (p.1).

Indeed, the intrinsic linguistic features of the Chinese language, such as the unique tonal phonetic system and the logographical script system, make it difficult for learners to master (Walton 1989). This makes it useful to develop a specific Chinese pedagogy to supplement generic methods and shared approaches. Chinese government-funded research and modern communications technology are both playing their part in reducing this problem, but almost nothing is known of Chinese language teaching methods using activities grounded in the most advanced theories of pedagogy (Orton 2011: 159). At the same time, little research on learning from largely traditional teaching methods of teacher model-students repeat, and constant revision and repetition has been conducted. In addition to the linguistic challenge, CFL teaching has to deal with the varied quality of the language teaching profession in China, which is regarded as the key obstacle in building capacity (Wang 2009 "Preparing and supporting teachers of less commonly taught languages"). One problem is that ability to use English as an international lingua franca is likely to be important for coping with the increasingly diverse students of Chinese. The wide spread of English around the world has resulted in many college-aged young adults using English as a lingua franca in cross-cultural communication. The large influx of such students into the CFL classroom has made it imperative that Chinese language teachers' pedagogical practices be examined in the light of the different cultures and languages brought into Chinese classroom.

As will be illustrated below, English is often used as a lingua franca in and outside the CFL classroom in China, amongst the multinational students of Chinese, and between the students and native Chinese teachers. In fact, as early as the first CFL program which was conducted in China in 1950, the CFL teacher used English as a lingua franca with the thirty three CFL students, all of whom came from Eastern European countries (Zhao 2009: 219). English then became a pariah language during the years of the Cultural Revolution and only resumed its importance after the Cultural Revolution (1976). Since then, CFL teacher training has focused on developing CFL teachers' contrastive linguistic awareness between the Chinese and English language (Zhang 2006: 98). In the 2000, however, the focus shifted to the teachers' English language competence. In some recent studies, CFL teachers are portrayed as messengers who spread Chinese culture in addition to the role of a language educator (Chen 2010: 11 "Hanyu guoji tuiguang yu duiwaihanyu jiaoxue"). This has increased the importance of English as a lingua franca (henceforth ELF) to keep the class communicative and interactive. In recent years, English was adopted as the medium of instruction for half of the core curriculum for the Master's program of Teaching Chinese to Speakers of Other Languages (MTCSOL) which was established in 2007 for providing sufficient CFL teachers and developing their intercultural understanding. Graduates of this program are expected to teach and communicate fluently in English. For CFL teachers employed to teach Chinese in the United States, United Kingdom and Australia, communication skills in English is regarded as an increasingly important pedagogical skill (Orton 2011: 154-158). Nevertheless, this emphasis on English is a highly contentious issue for many 
CFL educators and teachers because the pedagogical tradition for CFL teaching has long been dominated by the Chinese-only principle.

CFL pedagogy and teacher training are comparatively underdeveloped. Very few solutions or models are in existence, which are theoretically sound to equip CFL teachers with knowledge of how to employ ELF as an instructional strategy into classroom practices. Research on code choice in Chinese language classrooms through empirical research remains limited. Thus, this study seeks to find out how CFL teachers perceive the role and status of using ELF in CFL teaching to international students in multilingual contexts.

\section{Literature review}

The monolingual approach has long been promoted by official policies in the field of foreign language teaching (cf. Macaro 2001; Phillipson 1992). However, current thinking, informed by recent pedagogical and sociolinguistic research, holds that a multilingual approach to code choice can enhance foreign language learning and serve important cognitive, communicative, and social functions in foreign language classrooms (Butzkamm and Caldwell 2009; Levine 2011; Littlewood and Yu 2009; Turnbull and Daily-O'Cain 2009; Swain, Kirkpatrick and Cummins 2010). Yet, in CFL teaching, the "Chinese-only principle" continues to be the dominant pedagogy. Article 20 of the Law on the Commonly Used Language and Script in China covers the policy for CFL teaching across China (Rohsenow 2004: 41). It states that Putonghua (Modern Standard Chinese) and the standardized Chinese characters should be taught in classes for foreigners who are learning Chinese. Moreover, the first and only teaching syllabus for beginners of Chinese (Yang 1999) explicitly states that English and other foreign languages should be forbidden in CFL classes. Following this, the $\operatorname{Hanban}^{1}$ (2002), the government office that oversees Chinese studies, issued a new set of teaching syllabuses saying that CFL teachers should "...maximize the target language and diminish the use of [English] as a medium of instruction" (p.3). Proponents of the Chinese-only principle follow the regulations laid down by the state language policy and teaching syllabuses. Over the past decade, there has been growing enthusiasm about developing and promoting the Chinese-only principle amongst Chinese language scholars, educators and teachers (Liu 2000: 351; Lü 1993: 84; Sun 2003: 101). In particular, Liu Xun (2006) pointed out that CFL teachers should strictly follow the "immersion approach" and use Chinese exclusively in class (p.118). The official line and dominant belief is that Chinese is best taught through Chinese only, and that the use of ELF or other languages the students are familiar with always results in negative transfer in the process of acquiring Chinese. Some Chinese scholars have even challenged the lingua franca role of English (Ma 2003; Wang 2007 "Duiwai hanyu jiaocai zhong de meijieyu wenti shishuo"; 2009 "Lun duiwaihanyu jiaocai shengci shiyi moshi"). They argued that the use of ELF in the CFL classroom would only help to fulfill the goal of spreading English, which would distort the very purpose for CFL teaching.

Despite a rigid language policy, there has been intensive debate on whether or not to use ELF in CFL classes. Opponents of the Chinese-only principle have argued against this position by providing empirical evidence that CFL teachers have in practice successfully applied the ELF pedagogy. In fact, such a bilingual stance is not new for CFL teaching. For example, Xu (2008) identified several ways for using ELF sensibly and 
judiciously in CFL teaching. Wang (2012 "The use of English as a lingua franca in teaching Chinese as a foreign language: A case study of native Chinese teachers in Beijing") suggested that CFL teachers need to become bilingual in Chinese and English in today's increasingly globalized teaching contexts. In addition, Xie, Huang and Li. (2007) and Wang (2010 "Putong gaoxiao duiwaihanyu zhuanye shuangyu jiaoshi de peixun yu jianshe") argued that CFL teachers should become Chinese and English bilinguals and the CFL teacher training should focus on developing pedagogical skills in English.

This study involves discussions of teachers' beliefs and the ways in which these belief systems were formed. That teacher beliefs have a direct effect on their teaching is understood. Ghaith (2004) described the construct of teacher beliefs as "comprehensive of several functions relative to beliefs about learning, teaching, program and curriculum, and the teaching profession more generally" (p. 280). Similarly, Borg (2006) pointed out that teacher beliefs comprise teachers' general pedagogical beliefs and those beliefs are of relevance to individual teaching situations. Richards (1996) argued that teachers' beliefs are "working principles or maxims which teachers consciously or unconsciously refer to as they teach" (p. 282). In describing what teachers' beliefs were and how they were formed, a number of language educators (e.g., Carless 2007; Crawford 2004; Levine 2003; Rolin-Ianziti and Brownlie 2002; Tsui 2007) have provided insightful examples. It's believed that teachers' beliefs can be shaped by many factors, including their own experiences as L2 learners, teacher training, teaching experiences, official policies, and through exposure to the views and beliefs of colleagues and superiors.

In this study, teacher participants' beliefs were classified following Macaro's (2001,; 2005 ,; 2009) "continuum of perspective". The continuum illustrates several distinct personal beliefs that teachers might hold regarding their potential code choice in the L2 class. At one end of the continuum, there is the "virtual position", a monolingual perspective, in favor of an exclusive L2 use. At the other end, there is the "maximal position", which acknowledges that exclusive L2 use is not attainable, and recognizes the value in using multiple codes though sometimes accompanied by a guilty feeling when resorting to non-L2 codes. There is also an "optimal position", which believes a judicious use of multiple codes at particular times could enhance learning. This actively promotes and practices a multilingual approach without any feelings of guilt or remorse. This study has adopted Macaro's analytical framework for describing the positions on the continuum. It further sought to construct a tentative model for the use of ELF as a mediating pedagogy in CFL teaching - an ELF pedagogy.

\section{Narrative inquiry}

This present study sought to provide a description of CFL teachers' language beliefs about code choice and was informed by narrative inquiry (Clandinin and Connelly 2000). Narrative inquiry is an excellent method of showing the unique ways that people deal with their dilemmas and challenges (Beattie 2000). Although a number of studies have examined the phenomena in a quantitative way by using questionnaires as a major instrument (see e.g., Levine 2003; Duff and Polio 1990), more recently narrative inquiry has widely been used in the survey of teachers' beliefs and identities (see e.g., Tsui 2007; Gu 2011). Narrative inquiry allows teachers to reconstruct their personal 
knowledge, helping them to become more aware of their actions and more able to be agents in their own practice (Telles 2000). The overall aim of this study was to let each participant tell their own story and explain their beliefs and attitudes towards ELF use in CFL teaching. It sought to answer the following three research questions: (1) what are CFL teachers' attitudes toward the use of ELF; (2) what factors contribute to these attitudes; and (3) what are the core functions for ELF use which are adopted by CFL teachers?

\section{Procedure}

This research chose a purposive sampling method, as the main goal was to find individuals who could provide rich and varied insights into the phenomenon under investigation so as to maximize what we can learn (Dörnyei 2007:126). Taking into account the heavy workload and each teacher's timetable, face-to-face interviews were limited to $30-40$ minutes each. In order to increase the richness and depth of the responses and to help in tracking and identifying themes from the transcripts, notes were taken during the interviews. During transcription of the interviews, emerging themes and similarities or differences among teachers' beliefs and strategies were noted. Field notes and interview transcripts were analyzed using systematic and thematic open coding techniques.

We now present the detailed findings from this study, beginning with a description of the participants' beliefs and then an analysis of the factors that shaped and influenced these beliefs, on which basis the core functions of ELF use will be summarized. Interview protocols were designed in English and translated into Chinese. Considering the variable English ability of CFL teachers, interviews were conducted in Chinese and translated into English. The italicized words quoted in this paper denoted these were English words used by the interviewees.

\section{Participants}

The research was conducted at four universities in Beijing which specialize in teaching Chinese as a foreign language. Together they employ 96 full-time CFL teachers. Based on purposive sampling, 24 CFL teachers from across the four universities were selected to participate in face-to-face interviews. There were 11 male and 13 female participants. These participants were all native Chinese language speakers, educated in China's universities. 15 had master's degrees and nine had PhDs. 15 majored in Chinese, four in English and five were graduates of the MTCSOL program mentioned earlier. Even though some of the participants had only recently completed their degrees, they had relatively rich teaching experience. Ten had been teaching CFL for longer than ten years, seven for more than five years and seven for less than five. With regard to their self-assessed English ability to manage CFL classes, 12 chose "good", seven opted for "fair", and some voluntarily reported their grades in College English Test. Five felt their English proficiency were limited because they graduated from college before the proficiency test was introduced. To summarize, all participants agreed that they knew some English, though no one thought their English have reached a native level. The demographic details of the participants are summarized in Table 1. 
Table 1 Demographics of teacher participants.

\begin{tabular}{lllll}
\hline Gender & Qualifications & Qualified areas & Teaching experience & English proficiency \\
\hline Male $=11$ & M.A. $=15$ & Chinese $=15$ & $1-5$ years $=7$ & Not certified $=5$ \\
Female $=13$ & PhD $=9$ & English $=4$ & $5-10$ years $=7$ & Fair $=7$ \\
& & MTCSOL $=5$ & $10-20$ years $=10$ & Good $=12$ \\
\hline
\end{tabular}

$(n=24)$

\section{Results}

This part reports the teachers' beliefs. 15 participants identified themselves as upholding the "Chinese-only principle" and were thus classified as belonging to the "virtual position"; seven were found to support the "maximal position" and two fitted the "optimal position". The proportion of teachers' attitudes towards the use of ELF in Chinese language classroom is shown in Table 2.

\section{The virtual position}

The 15 teachers who were classified as holding the virtual position showed a firm belief in the Chinese-only principle. They provided 51 comments and their ideas were further grouped into five themes and 11 sub-themes, as shown in Table 3. In particular, these 15 teachers' views appear to have been influenced by the language policy, their understanding of L1 and L2 acquisition, national and language identity, their own English language competence, as well as by many unproven assumptions and perceived dangers concerning the use of ELF in the CFL classroom.

\section{Influence of language policy}

Five participants expressed the view that CFL teachers were expected to practice what the language policy and teaching syllabus preached. When these five teacher participants were asked to define their beliefs about language use in their classes, their answers were remarkably uniform. For example, T3 argued:

Our school has a very strict rule of prohibiting the use of English. Every teacher knows it. As you can see along the corridors, posters and banners are plentiful on the walls reminding our students about speaking Chinese only. It's our responsibility to hold to the rule and help students to obey it.

Similarly, T9 and T19 also indicated that their universities promoted the exclusive use of the target language as a key feature for CFL education. CFL teachers have to abide by the Chinese-only policy and offer a role model for their students. T7 and T24 believed that CFL teachers should simply go along with the policy as set by the university, but without giving much consideration to this issue.

Table 2 Proportion of teacher participants' general attitudes towards ELF use.

\begin{tabular}{lll}
\hline & Responses & Participants \\
\hline Virtual position & $15 / 24(62.5 \%)$ & $T 1,2,3,7,8,9,11,13,14,18,19,20,21,22,24$ \\
Maximal position & $7 / 24(29.2 \%)$ & $T 4,5,6,10,12,15,17$ \\
Optimal position & $2 / 24(8.3 \%)$ & $T 16,23$ \\
\hline$(n=24)$ &
\end{tabular}


Table 3 Comments in favor of the virtual position.

\begin{tabular}{lr}
\hline Themes & Total \\
\hline $\begin{array}{l}\text { 1. Influence of language policy } \\
\text { language policy should be abided by }(T 3,7,9,19,24)\end{array}$ & 5 \\
2. Perceptions of $L 2$ acquisition & 3 \\
L2 acquisition equals $L 1$ acquisition $(T 13,20,21)$ & 5 \\
one's $L 2$ learning has no relation to one' $L 1(T 7,11,18,20,24)$ & \\
3. Sinophone identity & 4 \\
national language pride should be upheld $(T 2,9,19,24)$ & 5 \\
codeswitching damaging one's Sinophone identity $(T 2,3,14,18,19)$ & 2 \\
do not accept themselves as bilingual speakers $(T 2,24)$ & 7 \\
4. English language competence & 3 \\
have no solid English speaking skills $(T 1,8,13,14,18,20,22)$ & \\
have no knowledge of teaching in English $(T 1,11,22)$ & 4 \\
5. Assumptions and perceived dangers & 7 \\
immersion program might be the most successful model $(T 1,7,18,19)$ & 6 \\
might cause injustice for non-English speakers $(T 2,9,11,14,19,20,21)$ & 51 \\
might lead to an overuse by students $(T 2,3,11,13,20,24)$ & \\
Total & \\
\hline
\end{tabular}

\section{Perceptions of L1 and L2 acquisition}

When further explaining the reason for their beliefs in the virtual position, many referred to their understandings of L2 acquisition. Although all teacher participants had completed their master's degrees and some had PhDs, their beliefs regarding language learning theory were surprisingly conservative. For instance, T13 felt that learning Chinese as a foreign language resembled learning one's mother tongue and thus the teaching method should be the same.

We all succeed in learning our mother tongue. Why? Recalling on how we learnt Chinese as children, we became native speakers by ear and imitation. There were no mediating languages helping us understand, right?

In addition to T13, 20 and 21 also believed that L1 and L2 acquisition were the same. However, five teacher participants felt that one's L2 learning has no relation to one's L1. They rejected that one's L1 and L2 could be interwoven and influence each other. For example, T7 said,

What they need to do is to forget their mother tongue as much and as quickly as possible. They should activate a part of the brain to speak and think in Chinese only. They need to drop all "crutches" and learn to walk on their own.

T7 regarded translation as unnecessary or even harmful. "Crutches" is a metaphor here for using ELF as a translation tool, where using English would cause interference in learning Chinese. In T7's opinions, CFL students were seen as "handicapped" in speaking Chinese, because they were struggling to achieve native proficiency. Moreover, T18 added that "students do not need to know why Chinese people speak it this way. All that they learners needed to do was to keep practicing with us and try to become native Chinese speakers." Furthermore, with regard to language transfer, T11, 
20 and 24 all argued that using more than one language would only result in an increasing "negative transfer", which was of great harm to L2 acquisition.

Sinophone identity

Interestingly, the interviews generated a considerable reflection about teachers' national pride and their Sinophone identity (McDonald 2011). Comments from T2, 9, 19 and 24 indicated a clear link between patriotism and speaking Chinese only. Their national pride was presented through stigmatizing the internationalization of English. For example, T9 expressed a strong antipathy towards English.

The Noble Prize winner, Ding Zhaozhong ${ }^{2}$ (Samuel Ting), delivered his speech in Chinese at the Award Ceremony and this broke the convention. He's the pride of all Chinese people. [...] Chinese is a great language. We should defend ourselves against the invasion of English. For me, I don't use a single English word in my class. Chinese language teachers are not simply a profession but also a national representative.

T9 further argued that CFL teaching was a "national profession shouldering the responsibility of spreading Chinese culture and showing China's soft power to the world". Furthermore, five teachers, T2, 3, 14, 18 and 19 believed codeswitching was a stain on their Sinophone identity. For example, T19 said

Responsible Chinese teachers should be role models for their students and help them speak Chinese like a native. As a Chinese teacher, we have responsibility to keep the purity of the Chinese language. [...] When I speak Chinese, I do not switch codes to English. It's too pretentious. Only fake foreigners switch codes.

T19 regarded codeswitching as the pretentious behavior of someone trying to act or speak like a foreigner and showing off their English. Yet, for many, T19's attitudes reflected the current battle of "saving Chinese from English" (The Economist 2010). At the 2010 Chinese People's Political Consultative Conference, Huang Youyi, the director of the China International Publishing Group, proposed measures to preserve the purity of Chinese language. He said

If we don't pay attention and don't take measures to stop the expansion of mingling Chinese and English, Chinese won't be a pure language in a couple of years. In the long run, Chinese will lose its role as an independent linguistic system for passing on information and expressing human feelings (cited in Wang 2010 "Beware of English invasion").

Many teachers argued that English was a threat to the purity of the Chinese language and even harmful to national cohesion. Moreover, their disapproval of a foreign language identity was a potential further influencing factor. T2 and T24 teachers felt uncomfortable about being labeled as bilinguals. They treated English "just as a tool" (Orton 2009: 93) and did not regard it as an integral part of their identity. In their views, bilingualism indicated a "subtractive" model (García 2009: 51), in which the improvement of English language would result in a degradation of one's authority and 
loyalty to the Chinese language. For example, T24 explained,

I don't think Chinese teachers are bilinguals. I do know that English is the first foreign language for most Chinese teachers, and they are using English to teach, but it is problematic if I am regarded as a bilingual teacher [...] It's very wrong to put English onto the same level as Chinese.

T24 saw those who used English in CFL class as unpatriotic and thus did not want to be seen as bilinguals, though she reported a high score in CET $6^{3}$. Moreover, T2 felt it's every CFL teachers' responsibility to keep English subordinate to their Chinese self. These two teacher participants rejected using of English in their classroom regardless of their English language proficiencies, but simply out of an identity-related concern.

\section{English language competence}

Unlike the above two cases, many teacher beliefs indeed have been influenced by their own English language proficiency and knowledge of foreign language teaching. Lack of English competence naturally prevents CFL teachers from using English in their class. Seven teacher participants felt unconfident in speaking English in front of international students, which explained their avoidance of using it. As T1 said,

Foreign language teaching in Europe and America is very different. Teachers seem to have a very equal relationship with their students. I want to learn from them, but I'm afraid my English is too limited to develop a close relationship with my students. I'd rather not bother with my broken English. I don't want to cause extra trouble or see my students laugh at me.

For T1, speaking in "broken" English would somehow diminish the teachers' authority in class. Moreover, T8, 13, 14, 18, 20 and 22 have all expressed their concerns over their English competence and attributed this to their unwillingness of using English in their classes. Furthermore, T1, T11 and T22 hesitated to speak English due to their insufficient knowledge of English vocabulary associated with Chinese culture. For example, T22 recalled

When I first got to teach Chinese, some of my students asked me what Chinese people eat for breakfast. I suddenly found I don't know how to say doujiang (soybean milk), huntun (won ton), baozi, (steamed bun), youtiao, (deep fried dough) [...] All that we have learnt in our English class are western food terms: "pizza", "hamburger" and "pasta". I think it's very important for Chinese language teachers to learn enough English terms for translating specific Chinese symbols.

T22 pointed out that what they have learnt in their English class was the English which would prepare them for living in an English speaking country. There seems to be a gap between what they have learnt and the English they actually need as Chinese language teachers in China. English terms for denoting particular Chinese symbols are increasingly useful for introducing Chinese culture. In general terms, while many CFL teachers' English could normally be described as proficient, they still have difficulties 
in explaining in English aspects of their language and culture, and the information available to them is often inadequate (Orton 2011:162).

\section{Assumptions and perceived dangers}

Teachers' beliefs were influenced through exposure to the perspectives of colleagues and supervisors, anecdotes and intuitions. Four teachers, T1, 7, 18, and 19, assumed an exclusive use of Chinese was the most effective way to help students reach a native level of proficiency. They favored an "immersion program", which is usually characterized by its rigorous monolingual teaching method and the extremely challenging "language pledge" for speaking Chinese only. In the interview, T18 praised the "Princeton in Beijing" program as being most successful. Its "total immersion" approach requires students to speak no language other than Chinese through taking a "language pledge". The text of the pledge is as follows:

I hereby pledge to use, in all my contacts, no language other than Mandarin Chinese for the duration of the program. I understand that failure to abide by the pledge will result in my dismissal from the program and forfeiture of tuition.

However, an immersion program of this type is probably more suitable for students who have prior knowledge and proficiency of Chinese. Studies have found that only those who have studied Chinese for at least two or three years' prior to their arrival in China will be able to "take optimal advantage" of the environment (Kubler 1997: 173). However, none of the four teachers who advocated such an immersion program and the exclusive use of Chinese expressed any concern over students' individual differences with regard their prior knowledge of Chinese, language aptitude, linguistic backgrounds, and their purposes and goals for studying Chinese.

Seven teachers (T2, 9, 11, 14, 19, 20 and 21) felt it unwise to use English, as some students might not know English. However, none has attempted to understand their students' English language proficiency because they felt that this was irrelevant to their teaching practices. They argued that they endeavored to keep the classroom equal by purposely avoiding the use of English in that "this is the only way out to keep everybody in the class equal". For example, T2 believed using English would make students from South Korea and Japan (two major groups constitute CFL students in China ${ }^{4}$ ) feel unfavorable.

Students from South Korea and Japan do not speak English at all. It will cause injustice in class. Students would question, why my teacher doesn't use my mother tongue? Why English? We want to keep the class equal. We should not make our students feel we only like to communicate with those from the U.S. and the U.K. This is the only way out to keep everybody in the class equal.

Although T2's notion about the English proficiency of students from Korea and Japan are inadequate, it remains common among many teachers (see eg., Wang 2007 "Duiwai hanyu jiaocai zhong de meijieyu wenti shishuo"). However, in fact, English cannot be considered as a "foreign language" any more in Korea, Japan and in many other countries in the so-called Expanding Circle (Kachru 1992; Honna 2008: 16). The recently published English Proficiency Index (English First 2011: 5), a benchmark for 
the assessment of international English proficiency, ranked South Korea $13^{\text {th }}$ and Japan $14^{\text {th }}$ out of 44 countries on an English proficiency scale, whereas the People's Republic of China only ranked $29^{\text {th }}$. In addition, it is clearly idealistic to expect that each individual should have the right to speak their mother tongue in multilingual classrooms; and it is impractical to expect Chinese language teachers to speak all languages. But equality and language justice are not maintained by depriving people completely of their linguistic resources by insisting on the Chinese-only principle.

Lastly, six teachers (T2, 3, 11, 13, 20 and 24) believed that, as most of their students were fluent English speakers, they were worried if they were to use English, their students would probably increase their use of English as well. As T20 said,

I'll never ask my students to waste time on translation, because if I use English to translate for them, they would rely on it and expect me to translate for them all the time. Students are here to learn Chinese, not English.

The last sentence - students are here to learn Chinese, not English - was repeatedly used when teachers were explaining their reasons for supporting the virtual position. Their view was that "the classroom is like the target country, therefore we should aim for total exclusion of the L1, and there is no pedagogical value in L1 use" (cf. Macaro 2001: 535). It's noteworthy that all fifteen participants in favor of the virtual position mentioned this as a reason at least once in their interviews.

\section{The maximal and optimal positions}

Seven teachers adopted the maximal position in agreeing to the use of as much Chinese as possible, but refusing to use it exclusively. In terms of resorting to other languages, they all expressed varying degrees of guilt. Indeed, there were only two teachers who felt completely free of guilt when using English in order to translate new lexical terms, explain sophisticated Chinese grammar or introduce Chinese culture, etc. The two groups of participants gave examples of when they used English as an international lingua franca in the CFL classroom. In total, these nine teachers provided 32 comments, which were grouped into three themes, namely, the scope of ELF pedagogy, three core functions of ELF pedagogy, and a personal function of ELF pedagogy as shown in Table 4.

Table 4 Comments in favor of the maximal and optimal position.

\begin{tabular}{lr}
\hline Themes & Total \\
\hline 1. The scope of ELF pedagogy & 6 \\
suitable for beginners with little to no prior knowledge $(T 4,6,10,15,17,23)$ & \\
2. Three core functions of ELF pedagogy & 7 \\
helpful for explaining Chinese linguistic knowledge $(T 4,5,10,12,15,16,17,23)$ & 3 \\
helpful for managing classroom $(T 5,6,10,12,16,17,23)$ & \\
helpful for encouraging interaction among students $(T 6,12,16)$ & 3 \\
3. Personal function of ELF pedagogy & 5 \\
to read and write English journal articles $(T 4,15,23)$ & 32 \\
to teach abroad and improve social mobility $(T 4,5,12,16,23)$ & \\
Total & \\
\hline
\end{tabular}




\section{The scope of ELF pedagogy}

Six participants (T4, 6, 10, 15, 17 and 23) described when they used ELF in CFL classes. They argued that English was especially useful for beginners' classes. For example, T4 recounted how she was made aware of language issues when she was asked to speak English by a group of absolute beginners of CFL from Europe. She said,

A group of European students came to me after the class and wondered if I spoke English. I said yes and then they felt relieved. They started to complain about their frustrating Chinese study for the first week in Beijing. I had no idea they could only understand a very small part of my instructions. [...] They've also told me about their difficulties in paying school fees, buying the right textbooks, logging into Internet. I thought what I was doing (use Chinese exclusively) was good for them, but it wasn't, at least, not desirable for beginners at all.

Many other teachers' comments strongly suggested that classes, especially beginners' classes, might benefit if taught bilingually in Chinese and English. For example, T17 argued that "it was unwise to practice the Chinese-only principle at the beginners' level, as it would cause too much anxiety and frustration." Similarly, T10 mentioned that some universities offer options for providing CFL classes using English, Korean or Chinese medium, and that these are very popular with students. If students are from the same language background, undoubtedly, their L1 would be the best mediating language to assisting their learning of Chinese. ELF pedagogy can benefit CFL beginners who speak English and are willing to use English to obtain the content-area knowledge and to exchange information.

\section{Three core functions of ELF pedagogy}

Three core functions for using ELF were identified in teachers' interviews. First, the teachers' use of English to interpret, translate or explain metalinguistic content of the Chinese language was categorized as the explanatory function. Second, their use of English to give routine instructions, praise, encourage, disapprove, plan assignments and prepare tests was classified as the managerial function. Third, the students' use of English to communicate with each other or provide peer support for each other was classified as the interactive function.

1. The explanatory function Eight teachers (T4, 5, 10, 12, 15, 16, 17 and 23) employed ELF in similar situations and indicated the importance of teaching Chinese with English comparatively. All these eight participants spoke English well. They argued that language was best taught through comparison. For instance, T5 gave an example of how she used ELF to explain a grammatical mistake (marked by an asterisk) made by one of her students.

My student said 我是病 (wo shi bing*, I am sick.). It's a very common mistake for beginners of Chinese. So I told my student it is a mistake. $\nabla$ (shi, be) in Chinese cannot be used in this way. You should say 我病了 (wo bing le, I am sick.), because the adjective can work as a predicate in Chinese, and no link verbs are needed.

T5 said that explaining Chinese grammar through ELF was playing a pedagogical role. Similarly, T10 used English to translate new terms and phrases. T15, 16 and 17 
used English to introduce Chinese cultural items, such as fengshui, Chinese lucky and unlucky numbers, and the basic strokes of Chinese characters. T23 mentioned that even advanced students may need translations or interpretations now and then, and thus it would be an advantage for CFL teachers to be able to understand English well and be prepared to use English in their daily teaching practice.

2. The managerial function Seven teachers (T5, 6, 10, 12, 16, 17 and 23) provided examples of English use for classroom management. They argued that English was particularly helpful when giving instructions. T23 felt that a persistence in doing routine activities in Chinese might result in teacher-fronted lessons in which individual students might only be speaking and practicing Chinese for small amounts of time. However, as T23 pointed out, teachers could achieve many linguistic and pedagogical goals in a very short time using English, leaving significantly more time for their students. For example T23 said,

If I want my class to divide into two groups and do some practice, I will say "two groups" and "pair work". [...] It saves a great amount of time! I don't want to spend my time on giving directions and maintain discipline. I don't think university teachers need to waste their time on classroom management.

T23 emphasized the efficiency brought by the use of English in her class. She argued that CFL students have plenty of L2 input outside classroom in Beijing, therefore teachers should focus on helping these adults learners understand the mechanism of the Chinese language and Chinese society, rather than keeping them disconnected by imposing a Chinese-only principle. Similarly, T16 argued that English use could help build a rapport between teachers and students.

They are not simply Chinese language learners. [...] They come all the way from a foreign country without knowing a soul here. They are still young students and they need help. Although my English isn't good enough, I'd still like to spend some time chatting with them on my class, to get to know where they are from, how's their life, what is their favorite food in Beijing. They learn the best when it comes to food.

T16 realized that CFL students studying abroad needed time to adapt to the local culture and life style. Language is not simply a means of expression or communication; rather, it is a practice that constructs, and is constructed by, the ways language learners understand their social surroundings and their possibilities for the future (Norton and Toohey 2004: 1). ELF was regarded as a useful way for CFL teachers and their students to get together, inside and outside class, for school study and for individual needs.

3. The interactive function Three teachers (T6, 12 and 16) argued that ELF was a good communicative tool to enhance interaction and collaboration among students in multilingual contexts. A typical CFL class in Beijing's universities consists of approximately ten to twenty international students, whose countries of origins and linguistic backgrounds are highly diverse. ELF can play an important role for such CFL students, especially while their knowledge of Chinese is limited. For example T6 said, 
I encourage my students to negotiate meanings in any languages they like as long as they truly understand what I'm teaching about. Using English is a strategy for me in the class. [...] Whenever I have some new Chinese words that I anticipate that most of my students do not know, I will ask those able students to translate into English in a louder voice. Then, the rest of class would understand the meaning of that Chinese word through English.

T6's perspective encourages student participation. She argued that codeswitching in English and Chinese can serve as a means to construct a multilingual space, where international CFL students could use English as a lingua franca for exchanging information and peer teaching to keep the class interactive.

\section{The personal function of ELF pedagogy}

Teachers reported that English was also helpful in many personal ways beyond the classroom. Three teachers (T4, 15 and 23) argued that a knowledge of English could bring extra opportunities, including publication, promotion, and most importantly, the possibility to teach Chinese overseas. As T15 recalled

I majored in English in university. [...] My good command of English helped me get many part-time jobs and thus working experience. If you want to publish your research paper into a high quality journal, you have to write "abstract" in English. Besides, you need to read English journals, participate in seminars and conferences where many people are speaking English for academic purpose. It's basically unthinkable if your English isn't good enough. [...] To keep the standard of my English, I'm listening to CRI every morning on my way to work. Practice makes perfect.

CRI is short for China Radio International, one of the few English radio programs in China which provides special broadcasts for Chinese English language learners. T15 had a keen interest in learning and using English and regarded himself as a life-long English language learner. T15 pointed out that he was under pressure to publish articles in international English language journals. Finally, five teachers (T4, 5, 12, 16 and 23) expressed a personal hope to teach Chinese abroad. For example, T12 said,

I want to teach Chinese abroad. [...] I submitted my application form to Hanban one week ago. I really wish this time I can make it. [...] Korea, I will be in Korea by next January if I succeed. It would be my first time to go abroad. [...] Of course, I don't speak Korean, so I need to speak English with my students. Otherwise, I will be deaf and dumb there.

\section{Discussion and conclusion}

This study has described CFL teachers in four Beijing universities and their perceptions and understandings of code choice in CFL teaching. Despite the rigid Chinese-only language policy, many participants believed that a cautious use of ELF could play an important role. An important finding is that many CFL teachers employ English as a de facto lingua franca. For CFL students with little to no proficiency in Chinese, their 
knowledge of English becomes a critical means for access to content-area knowledge. Therefore, we propose that an "ELF pedagogy" which effectively incorporates ELF into CFL teaching and learning across three functions, namely, explanatory, managerial and interactive, can be useful.

This is supported by previous research. Swain and Lapkin (2000: 258), Polio and Duff (1994: 317), Cook (2001: 413-419) and Eldridge (1996) have all proposed judicious use of multiple codes in L2 classes. In the context of CFL teaching, the model consists of three functions: (1) the explanatory function: the use of ELF to interpret, translate or explain metalinguistic content of the Chinese language and Chinese culture (cf. also Polio and Duff 1994: 320; Levine 2011; Butzkamm and Caldwell 2009); (2) the managerial function: the use of ELF to give routine instructions and feedback, to encourage, disapprove, plan assignments and prepare tests (cf. also Chambers 1992; Macaro and Mutton 2002); and (3) the interactive function: the use of ELF to encourage learnerlearner collaboration (cf.also McMillan and Rivers 2011; Antón and DiCamilla 1998; Macaro 2000: 184). This study suggests that there are many different types of learner with different learning styles and preferences, and many different learning settings. In practice, therefore, CFL teachers might need to adopt "instructional relativism" (Walton 1989: 21), through which they respect the multilingual and multinational reality of their particular Chinese classroom, and use ELF when appropriate as a vital, flexible and adaptable way to teach Chinese.

An important issue which emerged concerning the exclusive use of Chinese concerned the building and maintenance of a Sinophone identity. The exclusive use of Chinese was regarded as sign of a pure Sinophone and mixing-codes as pro-foreign. CFL teachers perceived that the job required them to show a strong national pride in front of foreigners by not mixing or borrowing. Practically speaking, however, given the impact of internationalization of English in higher education in China (Feng 2007; Kirkpatrick 2011), it may not be appropriate to treat codeswitching with English as ad hoc and necessarily detrimental. As Tsui (2005) pointed out, many Asian countries are in the process of reinventing national identity, while at the same time legitimising the hegemony of English by making it a central feature of national development. In most cases, this paradox is resolved by appropriating English in ways which do least damage to national language and identity. The findings of this study underscore the need for concrete but theoretically- motivated guidelines for CLF classroom language use that indicate which sorts of codeswitching behaviors facilitate L2 acquisition and which behaviors undermine it.

The one-size fits-all Chinese-only policy has long played a dominant role in Chinese language teaching. This study suggests, however, that CFL teachers might need to rethink and reexamine the overarching language policy and develop an alternative pedagogy, which allows the use of ELF in CFL classrooms in judicious ways, all of which are aimed at helping the learner learn the target language, particularly, though not exclusively in beginners' classes. The use of ELF is likely to become even more helpful as CFL classrooms become increasingly diverse and multilingual. However, teachers and students alike are not usually overtly aware of "how, when, and the extent to which" (Polio and Duff 1994: 320) they actually make code choices. A handbook for the use of Cantonese in Hong Kong's English classes, recently published by Swain, Kirkpatrick and Cummins (2011) has helped teachers have a "guilt-free" life when 
using the L1 in foreign language classrooms. Similarly, what is needed for CFL teachers are guidelines for them to consult and debate, and therefore improve their pedagogical skills in order to meet the challenges brought by the increasingly diverse nature of today's Chinese language classrooms.

\section{Endnotes}

${ }^{1}$ Hanban is the colloquial abbreviation for the Chinese National Office for Teaching Chinese as a Foreign Language, a non-government and non-profit organization affiliated with the Ministry of Education of the People's Republic of China.

${ }^{2}$ Samuel Ting was awarded the Nobel Prize in Physics in 1976. Although there had been Chinese recipients before, none had previously delivered the acceptance speech in Chinese.

${ }^{3}$ CET 6 is a national English as a Foreign Language test in the People's Republic of China, in which the certificate-holders have reached the English level of non-English major postgraduates.

${ }^{4}$ Numbers: According to statistics released by the China Association for Foreign Students Affairs (CAFSA), there were 265,090 CFL students in China (excluding those studying in Taiwan, Hong Kong and Macau) in 2010. The number of CFL students from South Korea accounted for the first, taking up $23.7 \%$ of the total CFL student population.

\section{Acknowledgements}

The authors would like to thank all teachers from the four universities who contributed to this study. Special thank also goes to the two anonymous reviewers for their comments and suggestions that greatly improved the manuscript.

\section{Author details}

${ }^{1}$ Department of English, the Hong Kong Institute of Education, 10 Lo Ping Road, New Territories, Hong Kong ${ }^{2}$ School of Languages and Linguistics, Nathan campus, Griffith University, 170 Kessels Road QLD 4111, Australia

\section{Authors' contributions}

DW carried out the investigation and drafted the paper; AK was the supervisor of DW when she was in her EdD program (of which this article described a part), who gave suggestions to the research design and revised DW's draft for final publication. Both authors read and approved the final manuscript.

\section{Competing interests}

The authors declare that they have no competing interests. But please note that the second-named author is the journal editor which is why his name was not included when the article was sent to review, in case this influenced the reviewers.

Received: 16 November 2011 Accepted: 24 January 2012 Published: 24 January 2012

References

Antón, Marta, and DiCamilla Federick. 1998. Socio-cognitive functions of L1 collaborative interaction in the L2 classroom. Canadian Modern Language Review 54(3): 314-342. doi:10.3138/cmlr.54.3.314.

Beattie, Mary. 2000. Narratives of professional learning: Becoming a teacher in learning to teach. Journal of Educational Inquiry 1(2): 1-23.

Borg, Simon. 2006. Teacher cognition and language educationLondon: Continuum.

Butzkamm, Wolfgang, and Caldwell John. 2009. The bilingual reform: A paradigm shift in foreign language teachingTübingen: Gunter Narr Verlag.

Carless, David. 2007. Student use of the mother tongue in the task-based classroom. ELT Journal 62(4): 331-338. doi:10.1093/ elt/ccm090.

Chambers, Gary. 1992. Teaching in the target language. Language Learning Journal 6: 66-67. doi:10.1080/ 09571739285200491.

Chen, Fu. 2010. Hanyu guoji tuiguang yu duiwaihanyu jiaoxue. In Hanyu guoji jiaoyu "san jiao" wenti: Di liu jie duiwaihanyu xueshu yantaohui wenji, ed. Beijing Language University. 1-12. Beijing: Foreign Language Teaching and Research Press.

In Teaching and learning Chinese: Issues and perspectives,ed. Jianguo Chen, Chuang Wang, Jinfa Cai. . Charlotte, N.C.: Information Age Pub.

Chen, Yea-Fen, and Hsin Shih-Chang. 2011. The development of TCSL teacher training in Taiwan. In Teaching and learning Chinese in global contexts, ed. Linda Tsung, Ken Cruickshank. 165-180. Continuum International Publishing Group. 
Clandinin, Jean, and Connelly Michael. 2000. Narrative inquiry: Experience and story in qualitative researchSan Francisco: Jossey-Bass.

Cook, Vivian. 2001. Using first language in the classroom. Canadian Modern Language Review 57(3): 402-423. doi:10.3138/ cmlr.57.3.402.

Crawford, James. 2004. Language choices in the foreign language classroom: Target language or the learners' first language? Regional Language Centre Journal 35(1): 5-20.

Dörnyei, Zoltán. 2007. Research methods in applied linguistics: Quantitative, qualitative, and mixed methodologiesOxford: Oxford University Press.

Duff, Patricia, and Polio Charlene. 1990. How much foreign language is there in the foreign language classroom? Modern Language Journal 74: 154-166. doi:10.1111/j.1540-4781.1990.tb02561.x.

Eldridge, John. 1996. Code-switching in a Turkish secondary school. ELT Journal 50(4): 303-311. doi:10.1093/elt/50.4.303.

English First. 2011. EF English Proficiency Index, English First.

In Bilingual education in China: Practices, policies, concepts,ed. Anwei Feng. . Clevedon: Multilingual Matters Ltd.

García, Ofelia. 2009. Bilingual education in the 21st century: a global perspectiveMalden, Mass.: Wiley-Blackwell Pub.

Ghaith, Ghazi. 2004. Correlates of the implementation of the STAD cooperative learning method in the English as a foreign language classroom. Bilingual Education and Bilingualism 7(4): 279-294. doi:10.1080/13670050408667813.

Gu, Mingyue. 2011. Language choice and identity construction in peer interactions: An insight from a multilingual university in Hong Kong. Journal of Multilingual and Multicultural Development 32(1): 17-31. doi:10.1080/01434632.2010.532876.

Hanban, . 2002. Gaodeng xuexiao waiguo liuxuesheng hanyu zhuanye jiaoxue dagangBeijing: Beijing University Press.

Honna, Nobuyuki. 2008. English as a multilingual language in Asian contexts: Issues and ideasTokyo: Kurosio Publishers.

Hu, Guangwei, and Alsagoff Lubna. 2010. A public policy perspective on English medium instruction in China. Journal of Multilingual and Multicultural Development 31(4): 365-382. doi:10.1080/01434632.2010.489950.

Kachru, Braj. 1992. Teaching world Englishes. In The other tongue: English across cultures, ed. Braj Kachru. 355-366. Chicago, IL: University of Illinois Press.

Kirkpatrick, Andy. 2011. Internationalization or Englishization: Medium of instruction in today's universities. Hong Kong. Centre for Governance and Citizenship Working Paper Series 2011/003. Institute of Education.

Kubler, Cornelius. 1997. NFLC guide for basic Chinese language programsWashington, DC: The National Foreign Language Center.

Levine, Glenn. 2003. Student and instructor beliefs and attitudes about target language use, first language use, and anxiety: Report of a questionnaire study. The Modern Language Journal 87: 343-364. doi:10.1111/1540-4781.00194.

Levine, Glenn. 2011. Code choice in the language classroomBristol: Multilingual Matters.

Li, Wei, and Hua Zhu. 2011. Changing hierarchies in Chinese language education for the British Chinese learners. In Teaching and Learning Chinese in Global Contexts, ed. Linda Tsung, Ken Cruickshank. 11-28. Continuum International Publishing Group.

Li, Wei. 2011. Moment Analysis and translanguaging space: Discursive construction of identities by multilingual Chinese youth in Britain. Journal of Pragmatics 43: 1222-1235. doi:10.1016/.jpragma.2010.07.035.

Littlewood, William, and Yu Baohua. 2009. First language and target language in the foreign language classroom. Language TeachingCambridge University Press.

Liu, Xun. 2000. Duiwaihanyu jiaoyu xue yinlunBeijing: Beijing Language University Press.

Liu, Xun. 2006. Hanyu zuowei di'er yuyan jiaoxue jianlunBeijing: Beijing Language University Press.

Lo Bianco, Joseph. 2007. Emergent China and Chinese: Language planning categories. Language Policy 6(1): 3-26. doi:10.1007/s10993-006-9042-3.

Lo Bianco, Joseph. 2011. Chinese: The Gigantic up-and-comer. In Teaching and learning Chinese in global contexts, ed. Linda Tsung, Ken Cruickshank. xiv-xxiv. London: Continuum.

Lü, Bisong. 1993. Duiwaihanyu jiaoxue yanjiuBeijing: Beijing Language University Press.

Ma, Qingzhu. 2003. Guanyu duiwaihanyu jiaoxue de ruogan jianyi. Shijie Hanyu Jiaoxue 3: 13-16.

Macaro, Ernesto, and Mutton Trevor. 2002. Developing language teachers through a co-researcher model model. Language Learning Journal 90(3): 320-337.

Macaro, Ernesto. 2000. Issues in target language teaching. In Issues in modern foreign language teaching, ed. Kit Field. 171-189. London: Routledge.

Macaro, Ernesto. 2001. Analysing student teachers' codeswitching in foreign language classrooms: Theories and decision making. The Modern Language Journal 85(4): 531-548. doi:10.1111/0026-7902.00124.

Macaro, Ernesto. 2009. Teachers' use of codeswitching in the second language classroom: Exploring 'optimal' use. In First language use in second and foreign language learning, ed. Miles Turnbull, Jennifer Dailey-O'Cain. 35-49. Bristol: Multilingual Matters.

Macaro, Ernesto. 2005. Codeswitching in the L2 classroom: A communication and learning strategy. In Non-native language teachers: Perceptions, challenges and contributions to the profession, ed. Enric Llurda. 63-84. New York, NY: Springer.

McDonald, Edward. 2011. Learning Chinese, turning Chinese: Challenges to becoming Sinophone in a Globalized worldLondon: Routledge.

McMillan, Brain, and Rivers Damian. 2011. The practice of policy: Teacher attitudes toward "English only". SYSTEM 39 251-263. doi:10.1016/j.system.2011.04.011.

Norton, Bonny, and Toohey Kelleen. 2004. Critical pedagogies and language learningCambridge: Cambridge University Press.

Orton, Jane. 2009. English and the Chinese quest. In China and English: Globalization and the dilemmas of identity, ed. Joseph Lo Bianco, Jane Orton, Yihong Gao. 79-97. Bristol: Multilingual Matters.

Orton, Jane. 2011. Educating Chinese language teachers - Some fundamentals. In Teaching and learning Chinese in global contexts, ed. Linda Tsung, Ken Cruickshank. 151-164. London: Continuum.

Phillipson, Robert. 1992. Linguistic imperialismOxford: Oxford University Press.

Polio, Charlene, and Duff Patricia. 1994. Teachers' language use in university foreign language classrooms: A qualitative analysis of English and target language alternation. The Modern Language Journal 78: 313-326. doi:10.1111/j.15404781.1994.tb02045.x.

Richards, Jack. 1996. Teachers' maxims in language teaching. TESOL Quarterly 28(1): 153-156. 
Rohsenow, John. 2004. Genesis of the language law of 2001. In Language policy in the People's Republic of China: Theory and practice since 1949, ed. Zhou Minglang, Sun Hongkai. 21-43. Boston: Kluwer.

Rolin-lanziti, Jeanne, and Brownlie Siobhan. 2002. Teacher use of learners' native language in the foreign language classroom. Canadian Modern Language Review 58: 402-426. doi:10.3138/cmlr.58.3.402.

Shum, Mark, Gao Fang, Tsung Linda, and Ki Wing Wah. 2011. South Asian students' Chinese language learning in Hong Kong: Motivations and strategies. Journal of Multilingual and Multicultural Development 32(3): 285-297. doi:10.1080/ 01434632.2010 .539693

Shum, Mark, Tsung Linda, and Gao Fang. 2011. Teaching and learning (through) Putonghua: From the perspective of Hong Kong teachers. In Teaching and learning Chinese in global contexts, ed. Linda Tsung, Ken Cruickshank. 45-62. London: Continuum.

Sun, Dejin. 2003. Duiwaihanyu jiaoxue yuyan yanjiu chuyi. Yuyan Wenzi Yingyong 3: 98-105.

Swain, Merrill, and Lapkin Sharon. 2000. Task-based second language learning: The use of the first language. Language Teaching Research 4: 253-276.

Swain, Merrill, Kirkpatrick Andy, and Cummins Jim. 2010. How to have a guilt-free life using Cantonese in the English Class: A handbook for the English Teachers in Hong KongHong Kong: Research Center in to Language Acquisition and Education in Multilingual Societies, Hong Kong Institute of Education.

Telles, João. 2000. Biographical connections: Experience as sources of legitimate knowledge. International Journal of Qualitative Studies in Education 13(3): 162-251.

The Economist. Chinese purism: Saving Chinese from English http://www.economist.com.hk/blogs/johnson/2010/12/ chinese_purism?page $=1$. Accessed 28 December 2010

Tse, Shek Kam, and Tan Wei Xiong. 2011. Catering for primary pupils with different Chinese language proficiencies in Singapore through differentiated curricula and instructional materials. In Teaching and learning Chinese in global contexts, ed. Linda Tsung, Ken Cruickshank. 29-44. London: Continuum.

Tsui, Amy. 2005. Language policy, culture and identity in the era of globalization. In IATEFL,ed. Briony Beaven. . Canterbury: IATEFL. 2005 conference selections.

Tsui, Amy. 2007. Complexities of identity formation: A narrative inquiry of an EFL teacher. TESOL Quarterly 41(4): 657-680.

In First language use in second and foreign language learning,ed. Miles Turnbull, Jennifer Dailey-O'Cain. . Bristol: Multilingual Matters.

Walton, Ronald. 1989. Chinese language instruction in the United States: Some reflections on the state of art. Journal or Chinese Language Teachers Association 1-42, Volume X, May, 1989.

Wang, Danping. 2010. A study of English as a lingua franca in teaching Chinese to speakers of other languages. The International Journal of Learning 17(6): 257-272.

Wang, Danping. 2012. The use of English as a lingua franca in teaching Chinese as a foreign language: A case study of native Chinese teachers in Beijing. In Language alternation, language choice and language encounter in international education,ed. Hartmut Haberland, Bent Preisler. . New York, NY: Springer.

Wang, Danrong. 2010. Putong gaoxiao duiwaihanyu zhuanye shuangyu jiaoshi de peixun yu jianshe. Xiandai Yuwen 21: 133-134.

Wang, Hanwei. 2007. Duiwai hanyu jiaocai zhong de meijieyu wenti shishuo. Shijie Hanyu Jiaoxue 2: 111-117.

Wang, Hanwei. 2009. Lun duiwaihanyu jiaocai shengci shiyi moshi. Yuyan Wenzi Yingyong 1: 124-133.

Wang, Jingqiong. 2010. Beware of English invasion. http://www.chinadaily.com.cn/china/2010npc/2010-03/10/ content_9564151.htm. Accessed 10 March 2010.

Wang, Shuhan. 2009. Preparing and supporting teachers of less commonly taught languages. Modern Language Journal 93(2): 282-287. doi:10.1111/j.1540-4781.2009.00860_8.X.

Xiao, Yun. 2011. Chinese language in the United States: An Ethnographic Perspective. In Teaching and learning Chinese in global contexts, ed. Linda Tsung, Ken Cruickshank. 181-197. London: Continuum.

Xie, Min, Huang Nannan, and Li Chunhua. 2007. Jiangxi gaoxiao duiwaihanyu zhuanye shuangyu jiaoxue xianzhuang fenxi. Yichun Xueyuan Xuebao (Shehui Kexue) 29(3): 117-119.

Xing, Zhiqun. 2009. Teaching and learning Chinese as a foreign language: A pedagogical grammarHong Kong: The Hong Kong University Press.

Xu, Pinxiang. 2008. Chuji jieduan duiwaihanyu ketang jiaoxue zhong meijieyu shiyong wenti tantao. Xiandai Yuwe 9 : 119-121.

Yang, Jizhou. 1999. Duiwaihanyu jiaoxue chuji jieduan jiaoxue dagangBeijing: Beijing Language University Press.

Yu, Baohua. 2010. Learning Chinese abroad: the role of language attitudes and motivation in the adaptation of international students in China. Journal of Multilingual and Multicultural Development 31(3): 301-321. doi:10.1080/ 01434631003735483.

Zhang, Hesheng. 2006. Duiwaihanyu jiaoshi sushi yu peixun yanjiu de huigu yu zhanwang. Beijing Shifan Daxue Xuebao (Shehui Kexue Ban) 3: 108-113.

Zhao, Jinming. 2009. Jiaoxue huanjing yu hanyu jiaocai. Shijie Hanyu Jiaoxue 2: 210-223.

Zhou, Minglang, and Sun Hongkai. 2004. Language policy in the People's Republic of China: theory and practice since 1949New York, NY: Springer .

doi:10.1186/2191-5059-2-3

Cite this article as: Wang and Kirkpatrick: Code choice in the Chinese as a foreign language classroom.

Multilingual Education 2012 2:3. 